\title{
Os centros de ciência e o ensino básico: formação de professores e divulgação científica
}

\author{
Science centers and elementary education: \\ teacher training and science communication
}

\author{
Tiago Eloy Zaidan \\ Professor, Curso de Comunicação Social/Faculdade Joaquim Nabuco. \\ eloyzaidan@gmail.com
}

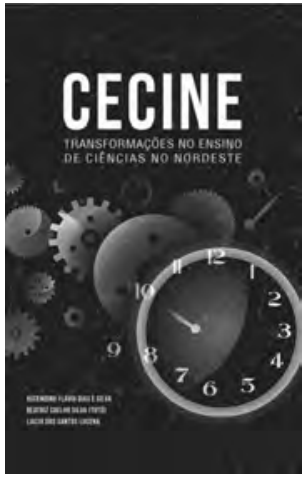

SILVA, Ascendino Dias e; SILVA, Beatriz Coelho; LUCENA, Liacir dos Santos (Org.). Cecine: transformações no ensino de ciências no Nordeste. Recife: EdUFPE. 2013. 251p.
$\mathrm{O}$ físico norte-americano Richard Feynman (1918-1988) já era famoso quando veio ao Brasil, na primeira metade da década de 1950. Chegou a desfilar em uma pequena escola de samba, no carnaval de 1952, conforme faz saber o físico pernambucano José Leite Lopes (1918-2006),

tocando uma frigideira com uma colher. Adorou as festas de carnaval, compareceu ao baile do Teatro Municipal fantasiado de Mefistófeles e neste baile foi buscar a saída de incêndio, uma preocupação que tinha em tais ambientes, quando encontrou a porta fechada à chave - de cujo paradeiro não tinham a menor ideia os auxiliares da portaria (citado em Silva, A., 2013a, p.24).

Em solo brasileiro, Feynman - que viria a ganhar o prêmio Nobel de Física em 1965 - colheu impressões sobre a educação no país, comentadas, mais tarde, no livro autobiográfico O senhor está brincando, Sr. Feynman? Aqui, o cientista relembra um episódio em que, ministrando aula para futuros professores, no mais avançado dos módulos, constatou a metodologia de como se "aprendia" física por

estas paragens. "Depois de muita investigação, descobri que os estudantes haviam decorado tudo, mas não sabiam o que queria dizer..." (citado em Silva, A., 2013a, p.22).

O nobelista notou também a deficiência dos livros de física elementar, em que resultados experimentais eram ilustres ausentes. Tais carências poderiam estar por trás do seguinte paradoxo: a despeito do notável quantitativo de estudo em física pelos jovens brasileiros, o país registrava um baixo número de físicos. A ineficiência dos métodos e instrumentos utilizados não gerava resultados.

As palavras do visitante corroborariam as ações pioneiras do professor Isaias Raw, diretor do Instituto Brasileiro de Educação, Cultura e Ciências (Ibecc), de São Paulo, órgão criado pela Organização das Nações Unidas para a Educação, a Ciência e a Cultura. Ciente das 
lacunas na literatura de física elementar em circulação no Brasil, Raw, por meio do Ibecc, articulava a tradução e a publicação de livros editados no bojo do projeto Physical Science Study Committee (PSSC) nos EUA.

A falta de estímulo dos estudantes para o aprendizado da física também havia sido um problema nos EUA. No contexto da Guerra Fria, com os avanços significativos da rival União Soviética no campo científico, o governo norte-americano passou a apoiar um projeto desenvolvido por professores de física do Massachusetts Institute of Technology, que redundou na publicação da série de livros do PSSC.

Isaias Raw, que esteve nos EUA em 1957 e conheceu o projeto, tornou-se articulador da publicação dos livros do PSSC no Brasil, ação que se transformou em um dos emblemas do Ibecc. O instituto, dirigido por Raw, acabou por inspirar o Ministério da Educação, ainda durante o governo João Goulart (1961-1964), com a tradução dos livros norte-americanos e a idealização de centros de ensino de ciências no país - rede que ficaria conhecida por Ceci.

O primeiro dos centros nasceu em Recife, no ano de 1963, a partir de um convênio entre a Universidade Federal de Pernambuco (UFPE), a Superintendência do Desenvolvimento do Nordeste (Sudene) e a Fundação Ford. Surgia assim o Centro de Ensino de Ciências do Nordeste (Cecine). Ao Cecine, ${ }^{1}$ seguiram-se a implantação do Centro de Ensino de Ciências de São Paulo; o Centro de Ensino de Ciências de Minas Gerais; o Centro de Ensino de Ciências da Bahia, o Centro de Ensino de Ciências da Guanabara² e, por fim, o Centro de Ensino de Ciências do Rio Grande do Sul, todos em 1965.

$\mathrm{O}$ advento do Cecine contou com o particular esforço do professor Marcionilo de Barros Lins. Diretor do Instituto de Química da então Universidade do Recife, futura UFPE, Marcionilo foi o primeiro gestor da entidade, cuja repercussão geraria um efeito em cadeia.Com os cursos,

estimulou-se o aparecimento de lideranças em vários estados, que se organizaram para criar outros núcleos de ensino de ciência com objetivos mais restritos. No Rio Grande do Norte, por exemplo, foi criado o Cetene, Centro de Tecnologia do Nordeste, para capacitação de professores das Escolas Técnicas Federais (Silva, A., 2013a, p.49).

Isto, em uma conjuntura na qual "havia uma carência quase absoluta de professores de ciências em Pernambuco, em particular, e no Nordeste, em geral” (Silva, B., 2013, p.58).

Tais centros se diferenciavam, sobretudo, pela metodologia experimental, com uso de equipamentos como laboratórios, propiciando uma nova visão para os docentes do ensino básico. Pari passu à consolidação dos empreendimentos, houve a publicação de materiais didáticos e oferecimento de cursos, aos quais se somaram as traduções de livros norteamericanos. Em muitos desses projetos, houve interação entre os centros.

Exemplo de obra publicada por um professor do Cecine é o opúsculo "Uma vela no laboratório", de Luiz de Oliveira, em 1967, cujo conteúdo "É um texto que apresenta uma série de experiências simples com uma vela" (Silva, A., 2013a, p.46) - passíveis, portanto, de ser apresentadas por professores secundaristas em suas escolas - além de versar sobre a história e a importância desse apetrecho no passado.

É sobre essa história de pioneirismo e dedicação à pavimentação de uma cultura científica no Brasil que versa a obra Cecine: transformações no ensino de ciências no Nordeste, organizado pelo professor da UFPE Ascendino Flávio Dias e Silva, em coautoria com a jornalista Beatriz 
Coelho Silva e o professor emérito da Universidade Federal do Rio Grande do Norte, Liacir dos Santos Lucena. O volume é composto por quatro artigos e um vasto apêndice, em que consta a transcrição de documentos da história da Cecine.

A concepção do livro é consequência de um projeto anterior, encetado pela professora Regina Maria Rabello Borges, da Pontifícia Universidade Católica do Rio Grande do Sul, cuja pesquisa inclui um resgate histórico dos centros de treinamento de professores de ciências. $\mathrm{O}$ artigo sobre a Cecine, no seio da pesquisa, fruto da investigação de Beatriz Silva, acabou inspirando a realização de um trabalho maior, que discorresse detalhadamente sobre o centro pernambucano.

A busca de recortes de jornais, fotografias e documentos que dessem conta da história da Cecine exigiu tempo e o apoio da Coordenação de Aperfeiçoamento de Pessoal de Nível Superior, através de edital do programa Pró-Cultura. O levantamento também não seria viável sem o mosaico possibilitado pela história oral. A colheita de depoimentos de pessoas que fizeram a história da Cecine ficou a cargo, sobretudo, da jornalista Beatriz Silva. Em menor escala, constam citações de depoimentos obtidos por Ascendino Silva e pelo também professor da UFPE Ari Luiz da Cruz, para um documentário em elaboração sobre a trajetória dos Cecis.

Um dos grandes méritos do livro é o de não resvalar para o ufanismo. Pressões vinculadas ao contexto histórico e os jogos de poder que permeiam praticamente qualquer atividade humana afetam, da mesma forma, as ciências e os esforços para popularizá-la. No artigo "Os centros de ensino de ciências em 1965", Dias e Silva versa, por exemplo, sobre o fato de que as relações dos Cecis com a ditadura militar instaurada a partir de março de 1964 foram contraditórias. Foi sob o jugo da ditadura que os centros de ciências passaram a funcionar efetivamente, inclusive o Cecine, embora os primeiros movimentos de articulação da rede tenham sido engendrados durante o governo de João Goulart. Parte significativa dos professores envolvidos com o projeto não concordava com o regime instituído após a deposição de Jango.

A maior ironia, todavia, ficou reservada ao destino do intelectual Isaias Raw, pioneiro que buscou nos EUA as bases que, adaptadas à realidade local, inspiraram a criação dos centros de ciências e revolucionaram a educação científica no país. Raw acabou exilado (Silva, A., 2013a, p.34) por uma ditadura patrocinada pelo governo norte-americano, o mesmo país que exportou os livros do PSSC.

Com o decorrer dos anos de chumbo, inicia-se uma nova fase dos Cecis, que

acontece no período em que o Brasil passa por ciclos que não foram muito bons para a educação nacional. Houve o período do Milagre Econômico (1969-1973) e em seguida a crise mundial do petróleo e o aumento da dívida externa, que fez o país amargar longo período de recessão (Silva, A., 2013b, p.116).

O governo federal, que se fazia presente por meio do Ministério da Educação e da Sudene, afasta-se dos centros de ciência e de seus programas de qualificação de professores. Em Pernambuco, o centro perde espaço e tem sua denominação alterada de "centro" para "coordenadoria".

Em meados da década de 1980, mergulhada na ressaca dos anos da ditadura, mesmo enfrentado escassez de recursos, a Cecine emplacou, graças ao apoio de professores aposentados, as escolinhas de iniciação científica. Oferecidas aos estudantes do ensino básico nos 
períodos de férias, a iniciativa era mantida pela inscrição dos alunos - o que possibilitava a realização das oficinas, o fornecimento de lanche e a remuneração e despesas de deslocamento dos monitores.

Ainda assim, o legado da Cecine era indubitável: "Quase dois mil professores passaram por seus laboratórios, cursos e estágios de formação ou treinamento, apenas entre 1965 e 1981" (Silva, B., 2013, p.55). Com o passar das décadas, pode-se dizer, a Cecine mudou o seu foco: de formadora de professores de ciência para iniciadora de jovens e adolescentes no mundo da ciência.

Somente na metade da década de 2000, na conjuntura da política de investimentos na rede federal de ensino superior, a Cecine recuperou parte do prestígio. Inserida na Pró-reitoria de Extensão da UFPE, o antigo centro beneficiou-se de editais oficiais, publicados por agências federais e estadual, para obter recursos e tocar projetos como a série de programas televisivos "Falando de ciência e tecnologia" e a série radiofônica "Ondas da ciência", exibidos nas emissoras do núcleo de rádio e televisão da UFPE e na TV Senado.

Cecine: transformações no ensino de ciências no Nordeste é um memorial à parte da história da ciência e de seu ensino no Brasil, especialmente no Nordeste. As conexões que a obra estabelece entre episódios do ensino de ciências no Brasil e a conjuntura sociopolítica a torna uma leitura para curiosos em geral. É interessante saber, por exemplo, como a viagem pioneira do cosmonauta soviético Yuri Gagarin ao espaço repercutiu no ensino de ciências no Brasil. O sucesso soviético foi o estopim para o desenvolvimento de uma nova metodologia na educação científica norte-americana, que, por sua vez, exportou seus métodos para o Brasil.

\section{NOTAS}

${ }^{1} \mathrm{O}$ Cecine, em dado momento, passou de centro a coordenadoria, motivo pelo qual, ao longo deste trabalho, ora é empregado o artigo masculino, ora, o artigo feminino, a depender do contexto temporal em que a sigla está inserida.

${ }^{2}$ Após a extinção da Guanabara, mudou de nome várias vezes. Atualmente é denominado Fundação Centro de Ciências e Educação Superior a Distância do Estado do Rio de Janeiro.

\section{REFERÊNCIAS}

SILVA, Ascendino Flávio Dias e.

Os centros de ensino de ciências em 1965. In: Silva, Ascendino Dias e; Silva, Beatriz Coelho; Lucena, Liacir dos Santos (Org.). Cecine: transformações no ensino de ciências no Nordeste. Recife: EdUFPE. p.17-51. 2013a.

SILVA, Ascendino Flávio Dias e.

A Cecine algum tempo depois. In: Silva, Ascendino Dias e; Silva, Beatriz Coelho; Lucena, Liacir dos Santos (Org.). Cecine: transformações no ensino de ciências no Nordeste. Recife: EdUFPE. p.115-133. 2013b.

SILVA, Beatriz Coelho.

Breve história do Cecine: como a verdade científica virou dúvida e experimentação. In: Silva, Ascendino Dias e; Silva, Beatriz Coelho; Lucena, Liacir dos Santos (Org.). Cecine: transformações no ensino de ciências no Nordeste. Recife: EdUPFE. p.53-113. 2013. 